\title{
Artesunate Inhibits the Growth Behavior of Docetaxel-Resistant Prostate Cancer Cells
}

\begin{abstract}
Olesya Vakhrusheva ${ }^{1}$, Holger H. H. Erb ${ }^{1,2}$, Vitus Bräunig ${ }^{1}$, Sascha D. Markowitsch ${ }^{1}$, Patricia Schupp ${ }^{1}$, Patrick C. Baer ${ }^{3}$, Kimberly Sue Slade ${ }^{1}$, Anita Thomas ${ }^{1}$, Igor Tsaur ${ }^{1}$, Martin Puhr ${ }^{4}$, Zoran Culig ${ }^{4}$, Jindrich Cinatl Jr ${ }^{5}$, Martin Michaelis ${ }^{6}$, Thomas Efferth $^{7}$, Axel Haferkamp ${ }^{1}$ and Eva Juengel ${ }^{1 *}$

${ }^{1}$ Department of Urology and Pediatric Urology, University Medical Center Mainz, Mainz, Germany, ${ }^{2}$ Department of Urology, University of Dresden, Dresden, Germany, ${ }^{3}$ Department of Internal Medicine III, Nephrology, University Hospital, GoetheUniversity, Frankfurt am Main, Germany, ${ }^{4}$ Department of Urology, Medical University of Innsbruck, Innsbruck, Austria, ${ }^{5}$ Institute of Medical Virology, Goethe-University, Frankfurt am Main, Germany, ${ }^{6}$ Industrial Biotechnology Centre and School of Biosciences, University of Kent, Canterbury, United Kingdom, 7 Institute of Pharmaceutical and Biomedical Sciences, Johannes Gutenberg University Mainz, Mainz, Germany
\end{abstract}

OPEN ACCESS

Edited by:

Jill Kolesar,

University of Kentucky, United States

Reviewed by: Krishna Beer Singh, University of Pittsburgh, United States

Mounir Tilaoui,

Waterford Institute of Technology,

Ireland

*Correspondence:

Eva Juengel

eva.juenge/@unimedizin-mainz.de

Specialty section:

This article was submitted to Pharmacology of Anti-Cancer Drugs,

a section of the journal

Frontiers in Oncology

Received: 04 October 2021 Accepted: 10 January 2022 Published: 07 February 2022

Citation: Vakhrusheva O, Erb HHH, Bräunig V, Markowitsch SD, Schupp P, Baer PC, Slade KS, Thomas A, Tsaur I, Puhr M,

Culig Z, Cinatl J Jr, Michaelis M, Efferth T, Haferkamp A and Juengel E (2022) Artesunate Inhibits the Growth Behavior of DocetaxelResistant Prostate Cancer Cells.

Front. Oncol. 12:789284. doi: 10.3389/fonc.2022.789284
Novel therapeutic strategies are urgently needed for advanced metastatic prostate cancer (PCa). Phytochemicals used in Traditional Chinese Medicine seem to exhibit tumor suppressive properties. Therefore, the therapeutic potential of artesunate (ART) on the progressive growth of therapy-sensitive (parental) and docetaxel (DX)-resistant PCa cells was investigated. Parental and DX-resistant PCa cell lines DU145, PC3, and LNCaP were incubated with artesunate (ART) [1-100 $\mu \mathrm{M}$ ]. ART-untreated and 'non-cancerous' cells served as controls. Cell growth, proliferation, cell cycle progression, cell death and the expression of involved proteins were evaluated. ART, dose- and time-dependently, significantly restricted cell growth and proliferation of parental and DX-resistant $\mathrm{PCa}$ cells, but not of 'normal, non-cancerous' cells. ART-induced growth and proliferation inhibition was accompanied by G0/G1 phase arrest and down-regulation of cell cycle activating proteins in all DX-resistant PCa cells and parental LNCaP. In the parental and DX-resistant PC3 and LNCaP cell lines, ART also promoted apoptotic cell death. Ferroptosis was exclusively induced by ART in parental and DX-resistant DU145 cells by increasing reactive oxygen species (ROS). The anti-cancer activity displayed by ART took effect in all three PCa cell lines, but through different mechanisms of action. Thus, in advanced PCa, ART may hold promise as a complementary treatment together with conventional therapy.

Keywords: prostate cancer (PCa), docetaxel (DX) resistance, artesunate (ART), Traditional Chinese Medicine (TCM), growth inhibition, apoptosis, ferroptosis

\section{INTRODUCTION}

Prostate carcinoma ( $\mathrm{PCa}$ ) is the most common cancer in men without curative therapy for metastatic disease, although diverse therapeutic strategies have contributed to prolonged survival and reduced therapy-induced complications (1-3). The chemotherapeutic agent docetaxel (DX) is one of the most effective drugs used to treat metastatic PCa (4). However, the efficacy of the DX- 
based therapy is limited to only a few months, due to therapy resistance (5-7). The sequential treatment with second-line therapeutics remains less effective (8). Due to existing and emerging resistance to DX, innovative therapeutic approaches are essential in bringing new effective treatment options to patients with castration- and chemotherapy-resistant PCa.

In the past decades, the demand for complementary and alternative medicine (CAM) has increased and is reflected by its use among cancer patients, ranging from 30 - 90\%, depending on the country, culture, cancer type and stage (9-11). Like pharmacological agents, combination therapy with natural compounds requires thorough investigation to increase efficacy while minimizing side effects. Since valid scientific investigation regarding the anti-tumor activity of natural compounds is frequently lacking, contraindications to their use cannot be ruled out $(12,13)$.

Artemisinin, extracted from Artemisia annua (Sweet Wormwood), was developed in Traditional Chinese Medicine to treat malaria (14). Artesunate (ART) (Figure 1A), derived from artemisinin, exhibits remarkable anti-cancer activity towards a broad variety of tumor cell lines $(15,16)$, including prostate carcinoma (17-19). Moreover, ART exhibits antiinflammatory properties, thereby preventing tissue destruction induced by carcinogens in vivo (20). An endoperoxide moiety of ART reacts with iron, leading to the formation of cytotoxic radicals (21). Cancer cells have elevated iron and transferrin receptor levels, compared to normal cells, thus, making them susceptible to reactive oxygen species (ROS) (22-24). In doxorubicin-resistant T-cell leukemia and cisplatin-resistant neuroblastoma, ART has been shown to trigger ROS formation, resulting in apoptosis induction $(25,26)$. ART has also caused cell cycle arrest in ovarian cancer cells via increased ROS generation (27). Besides initiating apoptotic cell death, ART induces ferroptosis, an iron-dependent programmed cell death in head and neck cancer (28). The resulting ART-mediated decrease in cellular glutathione $(\mathrm{GSH})$ and accumulation of lipid ROS levels abrogated cisplatin resistance in these cells. In addition, ART activates ferroptosis in pancreatic carcinoma cells bearing oncogenic Ras (29). The anti-cancer activity of ART is therefore multifaceted. The goal of the present study was to investigate ART's mode of action in a panel of therapy-sensitive (parental) and DX-resistant prostate cancer cells.

\section{MATERIALS AND METHODS}

\subsection{Isolation and Cultivation of Primary Human Renal Tubular Epithelial Cells}

Primary human renal tubular epithelial cells (TEC) served as 'normal, non-cancerous' control cells. TEC were separated, cultured and characterized as described previously $(30,31)$. In brief, cells were isolated after tumor nephrectomies from renal tissue not involved in renal cell carcinoma. The donors gave written informed consent. Ethical standards were complied with as defined by the World Medical Association Declaration of Helsinki. The tissue was disintegrated using crossed blades, digested with collagenase/dispase, and passed through a 106 $\mu \mathrm{m}$ mesh. Remaining cohered cells were then incubated with collagenase IV, DNase and $\mathrm{MgCl}_{2}$ and further purified by Percoll density gradient centrifugation (31). After centrifugation, the fraction between 1.05 and $1.076 \mathrm{~g} / \mathrm{ml}$ was collected and washed twice in three volumes of ice cold HBSS (Gibco, Thermo Fisher Scientific, Darmstadt, Germany). Isolated cells were seeded in 6well plates. Medium 199 (M4530, Sigma, Taufkirchen, Germany) with a physiologic glucose concentration $(100 \mathrm{mg} / \mathrm{dl})$ was supplemented with $10 \%$ fetal bovine serum (FBS; Biochrom, Berlin, Germany), used as standard culture medium and replaced every three to four days. Confluent cells were passaged by trypsinization. Cells between passages 2 and 5 were used for the experiments.

\subsection{Cell Lines}

The PCa cell lines DU145, PC3, and LNCaP were purchased from the German Collection of Microorganisms and Cell Cultures (DSMZ). The DX-resistant sublines were derived from the Resistant Cancer Cell Line (RCCL) collection (http:// research.kent.ac.uk/industrial-biotechnology-centre/theresistant-cancer-cell-line-rccl-collection/). Drug-adapted cancer sublines were established by continuous exposure to stepwise increasing drug concentrations as previously described $(32,33)$. DX-sensitive (parental) DU145, PC3, and their respective DXresistant sublines were cultivated in RPMI-1640 medium (Gibco, Thermo Fisher Scientific, Darmstadt, Germany). Parental LNCaP and the DX-resistant subline were sub-cultured in Iscove Basal medium (Biochrom $\mathrm{GmbH}$, Berlin, Germany). Media were supplemented with $10 \%$ fetal calf serum (FCS) (Gibco, Thermo Fisher Scientific, Darmstadt, Germany), 1\% glutamax $\left(\right.$ Gibco $^{\circledR}$, Thermo Fisher Scientific, Darmstadt, Germany), and 1\% Anti/Anti (Gibco, Thermo Fisher Scientific, Darmstadt, Germany). 20 mM HEPES-buffer (Sigma-Aldrich, Darmstadt, Germany) was added to the RPMI-1640 medium. The DX-resistant sublines were exposed to 12.5 nM DX (SigmaAldrich, Darmstadt, Germany) three times a week. All cell lines were cultivated in a humidified, $5 \% \mathrm{CO}_{2}$ incubator.

\subsection{Drug Treatment}

ART (Sigma-Aldrich, Darmstadt, Germany), dissolved in DMSO, was applied for 24,48 , or $72 \mathrm{~h}$ at a concentration of 1-100 $\mu \mathrm{M}$. Controls (parental and cisplatin-resistant) remained ARTuntreated. To evaluate toxic effects of ART, cell viability was determined by trypan blue (Sigma-Aldrich, Darmstadt, Germany). Ferrostatin-1 (Sigma-Aldrich, Darmstadt, Germany), the ferroptosis inhibitor, was used at a concentration of $20 \mu \mathrm{M}$.

\subsection{Cell Growth and Proliferation}

Cell growth was defined using 3-(4,5-dimethylthiazol- 2-yl)-2,5diphenyltetrazolium bromide (MTT) dye. PCa DX-sensitive and DX-resistant cells $\left(50 \mu \mathrm{L}, 1 \times 10^{5}\right.$ cells $\left./ \mathrm{mL}\right)$ were seeded into 96well-plates. ART (Sigma-Aldrich, Darmstadt, Germany) was applied for 24,48 , and $72 \mathrm{~h}$ at a concentration of 1-100 $\mu \mathrm{M}$. Then, MTT (0.5 mg/mL) (Sigma-Aldrich, Darmstadt, Germany) was added. After $4 \mathrm{~h}$ incubation with MTT, cells were lysed with $100 \mu \mathrm{L}$ solubilization buffer per well containing $10 \%$ SDS in 0.01 
A

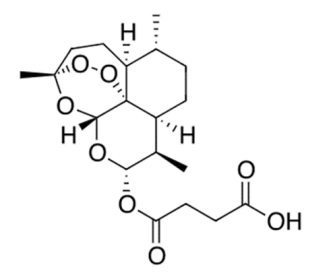

C

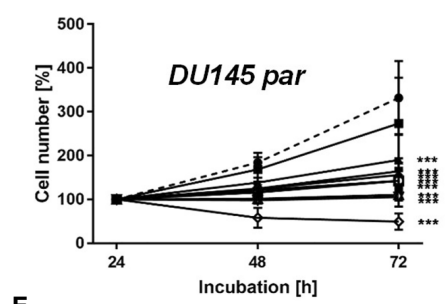

E

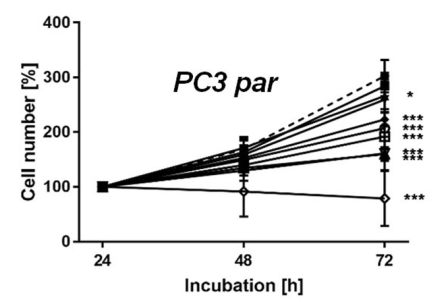

G

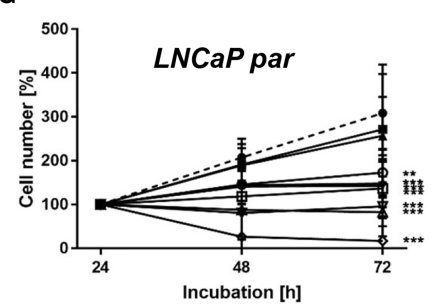

B
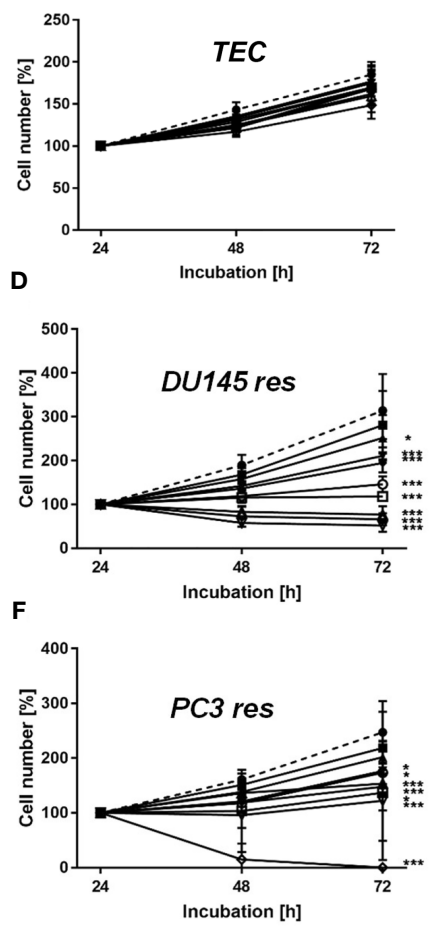

H

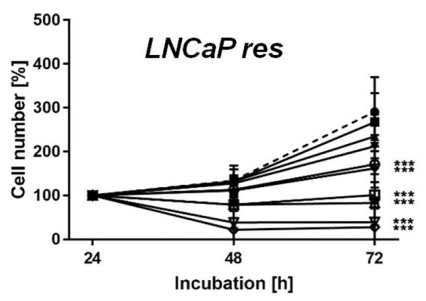

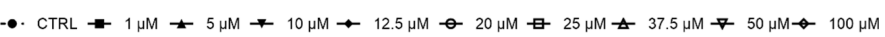

FIGURE 1 | Chemical structure of ART (A) and cell growth of normal (healthy) TEC cells (B) as well asof parental (par) and DX-resistant (res) DU145 (C, D), PC3 (E, F), and LNCaP (G, H) PCa cells after 24, 48, and $72 \mathrm{~h}$ incubation with ART concentrations ascending from $1-100 \mu \mathrm{M}$. Untreated cells served as controls. Cell number was set to $100 \%$ after $24 \mathrm{~h}$ incubation. Error bars indicate standard deviation (SD). Significant difference to untreated control: ${ }^{*} p \leq .05,{ }^{* *} p \leq .01,{ }^{* * *} p \leq .001$. $n=3$.

$\mathrm{M} \mathrm{HCl}$. The plates were then incubated overnight at $37^{\circ} \mathrm{C}$ in a $5 \%$ $\mathrm{CO}_{2}$ incubator. Absorbance at $570 \mathrm{~nm}$ was determined for each well using a multi-mode microplate-reader (Tecan, Spark $10 \mathrm{M}$, Crailsheim, Germany). After subtracting background absorbance and offsetting with a standard curve, results were expressed as mean cell number in percent. To illustrate dose-response kinetics, the mean cell number after $24 \mathrm{~h}$ incubation was set to $100 \%$. Each experiment was done in triplicate.

Cell proliferation was measured using a BrdU (Bromodeoxyuridine/5-bromo-2'-deoxyuridine) cell proliferation enzyme-linked immunosorbent assay (ELISA) kit (Calbiochem/ Merck Biosciences, Darmstadt, Germany). Cells $\left(50 \mu \mathrm{L}, 1 \times 10^{5}\right.$ cells $/ \mathrm{mL}$ ) were seeded into 96-well-plates and incubated with ART for $48 \mathrm{~h}$ at concentrations from 12.5 to $100 \mu \mathrm{M}$. $20 \mu \mathrm{L}$ BrdUlabeling solution per well was added $24 \mathrm{~h}$ prior to fixation and staining using anti-BrdU mAb, according to the manufacturer's protocol. Absorbance was measured at $450 \mathrm{~nm}$ using a multimode microplate-reader (Tecan, Spark 10 M, Crailsheim, Germany). Values presented as percentage compared to untreated controls were set to $100 \%$.

\subsection{Cell Cycle Analysis}

To investigate cell cycle progression of ART-treated and control PCa cells, $1 \times 10^{6}$ cells were stained with propidium iodide (PI) $(50 \mu \mathrm{g} / \mathrm{mL})$ (Invitrogen, Thermo Fisher Scientific, Darmstadt, Germany) and analyzed by flow cytometry (Fortessa X20, BD Biosciences, Heidelberg, Germany). Data acquisition was carried out using DIVA software (BD Biosciences, Heidelberg, Germany), and cell cycle phase distribution was analyzed by ModFit LT 5.0 software (Verity Software House, Topsham, ME, 
USA). The number of cells in the G0/G1, S, or G2/M phases was expressed as a percentage.

\subsection{Cell Death (Apoptosis, Necrosis, Ferroptosis)}

The FITC-Annexin V Apoptosis Detection kit (BD Biosciences, Heidelberg, Germany) was used to quantify apoptotic and necrotic events. After washing cells twice with PBS, $1 \times 10^{5}$ cells were resuspended in $500 \mu \mathrm{L}$ of $1 \times$ binding buffer and incubated with 5 $\mu \mathrm{L}$ Annexin V-FITC and/or $5 \mu \mathrm{L}$ PI in the dark for $15 \mathrm{~min}$. Staining was measured by flow cytometer (Fortessa X20, BD Biosciences, Heidelberg, Germany). The percentage of apoptotic and necrotic cells was calculated using DIVA software (BD Biosciences, Heidelberg, Germany). Further analysis was done by FlowJo software (BD Biosciences, Heidelberg, Germany).

To evaluate ferroptosis, cells were treated with $37.5 \mu \mathrm{M}$ ART or ART combined with the ferroptosis inhibitor ferrostatin-1 [20 $\mu \mathrm{M}]$ (Sigma-Aldrich, Darmstadt, Germany) for 24 and $48 \mathrm{~h}$. Ferroptosis was assessed using BrdU cell proliferation enzymelinked immunosorbent assay (ELISA) kit (Calbiochem/Merck Biosciences, Darmstadt, Germany), as described above. For more details, see Cell Growth and Proliferation (2.4).

\subsection{Western Blot Analysis of Cell Cycle and Cell Death Regulating Proteins}

The expression and activity of cell cycle and cell death regulating proteins were explored by Western blot analysis. Tumor cell lysates $(50 \mu \mathrm{g})$ were applied to 10 or $12 \%$ polyacrylamide gel and separated for $10 \mathrm{~min}$ at $80 \mathrm{~V}$ and $1 \mathrm{~h}$ at $120 \mathrm{~V}$. The protein was then transferred to nitrocellulose membranes $(1 \mathrm{~h}, 100 \mathrm{~V})$. After blocking with $10 \%$ non-fat dry milk for $1 \mathrm{~h}$, the membranes were incubated overnight with the following primary antibodies directed against cell cycle regulating proteins: CDK1 (Mouse IgG1, clone 2), CDK2 (Mouse IgG2a, clone 55), cyclin A (Mouse IgG1, clone 25), cyclin B (Mouse IgG1, clone 18), and cyclin D1 (Rabbit IgG, clone 92G2), (all: BD Biosciences, Heidelberg, Germany).

To indicate apoptosis and ferroptosis-related proteins, the following primary antibodies against the corresponding proteins (total expression) were used: caspase 3 (Rabbit, pAb), caspase 8 (Rabbit IgG, clone D35G2), PARP-1 (Rabbit IgG, clone 46D11), (all Cell Signaling, Frankfurt am Main, Germany), and GPX4 (Rabbit IgG, ab41787, Abcam, Berlin, Germany). HRP-conjugated rabbit-anti-mouse IgG or goat-anti-rabbit IgG served as secondary antibodies (IgG, both: dilution 1:1000, Dako, Glostrup, Denmark). The membranes were incubated 2 min with an ECL detection reagent (AC2204, Azure Biosystems, Munich, Germany) to visualize proteins with a Sapphire Imager (Azure Biosystems, Munich, Germany). Protein expression was normalized to total protein. To quantify total protein all membranes were stained with Coomassie brilliant blue and measured by Sapphire Imager. AlphaView software (ProteinSimple, San Jose, CA, USA) was used for pixel density analysis of the protein bands. The ratio of protein intensity $/ \beta$-actin intensity or whole protein intensity was calculated and expressed in percentage, related to the untreated control, set to $100 \%$.

\subsection{GSH Assay}

The GSH level was evaluated using the GSH-Glo ${ }^{\mathrm{TM}}$ Glutathione Assay (Promega GmbH, Walldorf, Germany). $5 \times 10^{3}$ cells/well were seeded into a 96-well plate and incubated for $24 \mathrm{~h}$ with 37.5 $\mu \mathrm{M}$ ART. Experiments were performed according to the manufacturer's protocol. Luminescence was measured using a multi-mode microplate-reader (Tecan, Spark $10 \mathrm{M}$, Tecan, Grödig, Austria).

\subsection{Statistical Analysis}

All experiments were performed at least three times. The evaluation and generation of mean values as well as normalization in percent were done with Microsoft Excel. The standard deviation and statistical significance was calculated with GraphPad Prism 7.0 (GraphPad Software Inc., San Diego, CA, USA): two-sided $t$-Test (Western blot, apoptosis, cell cycle), oneway ANOVA test (BrdU), and two-way ANOVA test (MTT). Correction for multiple comparisons was done using the conservative Bonferroni method. Differences were considered statistically significant at a $p$-value $\leq .05$.

\section{RESULTS}

\subsection{ART Inhibits Cell Growth and Proliferation of Parental and DX-Resistant PCa Cells}

Tumor cell growth and proliferation of parental and DX-resistant PCa cells as well as of 'normal/non-tumor' cells were evaluated after ART application. Growth of ART-treated 'normal' cells, here primary human renal tubular epithelial cells (TEC), remained unchanged, compared to the untreated cells (Figure 1B). In contrast, ART induced a significant time- and dose-dependent growth inhibition in parental and DX-resistant DU145, PC3, and LNCaP cells (Figures 1C-H). Parental and DX-resistant DU145 and LNCaP cells showed similar growth inhibitory effects after $72 \mathrm{~h}$ exposure to ART (Figures 1C, D, G, H). In contrast, DX-resistant PC3 cells responded more sensitively to ART than their parental counterparts (Figures 1E, F). Both parental and DX-resistant DU145 cells revealed first significant growth inhibition after $72 \mathrm{~h}$ at an ART concentration of $5 \mu \mathrm{M}$ (Figures 1C, D). Parental PC3 cells also showed growth inhibition at $5 \mu \mathrm{M}$ ART. DX-resistant PC3 cells first displayed growth inhibition at $10 \mu \mathrm{M}$ ART, but showed a total response, leaving no more cells at the highest concentration of $100 \mu \mathrm{M}$ (Figure 1F). In parental PC3 cells, 100 $\mu \mathrm{M}$ ART induced a decrease in cell number but did not lead to the death of all cells (Figure 1E), as seen with the DX-resistant PC3 cells (Figure 1F). LNCaP cells, both parental and DX-resistant, responded with a significant reduction of tumor cell growth at 20 $\mu \mathrm{M}$ ART. Since treatment with $37.5 \mu \mathrm{M}$ showed a strong growth inhibitory effect in all tested cell lines, $37.5 \mu \mathrm{M}$ ART and higher concentrations were used in the following experiments.

In line with the growth data, proliferation of all parental and DX-resistant PCa cells was significantly diminished in a dosedependent manner after exposure to ART for $48 \mathrm{~h}$ (Figures 2A-F). 

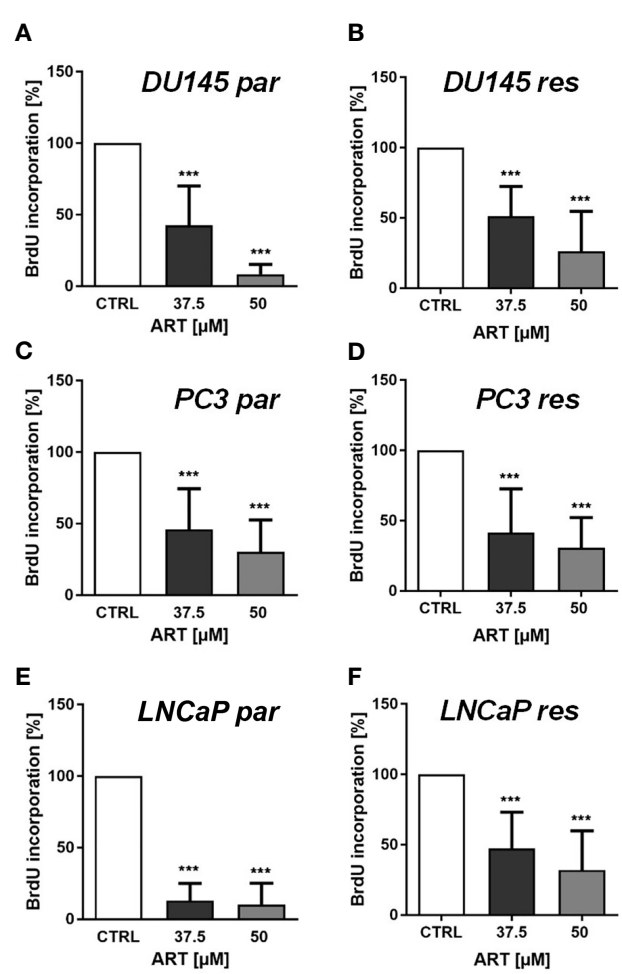

FIGURE 2 | Tumor cell proliferation of parental (par) and DX-resistant (res) DU145 (A, B), PC3 (C, D), and LNCaP (E, F) cells incubated for $48 \mathrm{~h}$ with ART [37.5 and $50 \mu \mathrm{M}$ ]. Untreated controls were set to $100 \%$. Error bars indicate standard deviation (SD). Significant difference to untreated control: ${ }^{* \star *} \mathrm{p} \leq .001 . \mathrm{n}=3$.

\subsection{ART Induces Cell Cycle Arrest, Accompanied by Alterations in the Expression of Cell Cycle Regulating Proteins}

In parental and DX-resistant PCa cells, ART-mediated cell growth inhibition and reduced proliferation were associated with impaired cell cycle progression. ART caused a significant G0/G1 phase arrest in DX-resistant DU145, PC3, and LNCaP cells (Figures 3A-C). The increase in G0/G1 phase was connected with a significant reduction in $\mathrm{S}$ phase (all) and G2/ $\mathrm{M}$ phase (DU145) cells (Figures 3A-C). Furthermore, ART resulted in a significant gain of G0/G1 phase cells and a simultaneous decrease of $\mathrm{S}$ and $\mathrm{G} 2 / \mathrm{M}$ phase cells in parental LNCaP cells (Figure 1C). In contrast, parental DU145 and PC3 cells showed no significant changes in cell cycle progression after treatment with ART (Figures 3A, B).

The G0/G1 cell cycle arrest in the PCa cells was accompanied by significantly diminished expression of regulating CDK-cyclin complexes (Figure 4). In DX-resistant DU145, DX-resistant PC3, and both parental and DX-resistant LNCaP cells, the cell cycle proteins responsible for successful $S$ and $G 2 / M$ phase progression, CDK1 (Figures $4 \mathbf{A}, \mathbf{B}, \mathbf{G}, \mathbf{H}, \mathbf{M}, \mathbf{N}$ and Figure S1.1, 1.6, 1.11) and CDK2 (Figures 4A, C, G, I, M, O and Figure S1.2, 1.7, 1.12), as well as cyclin A (Figures 4A, D, G, J, M, P and Figure S1.3, 1.8, 1.13) were significantly downregulated in response to ART. Moreover, DX-resistant PC3 and parental and DX-resistant LNCaP cells revealed a significant decrease of cyclin B (Figures 4G, K, M, Q and Figure S1.9, 1.14), involved in $G 2 / M$ phase progression, and cyclin $D 1$ (Figures 4G, L, M, R and Figure S1.10, 1.15), responsible for G0/G1 phase progression. Also in the parental DU145 and PC3 cells expression of some activating proteins were impaired, however without affecting cell cycle regulation.

\subsection{Artesunate Induces Apoptotic Cell Death in PCa Cells}

Since changes in cell cycle progression after ART treatment could not explain the observed growth and proliferation inhibition in all three PCa cell lines, apoptosis was assessed. No apoptotic events were detected after exposure to ART in parental and DXresistant DU145 cells, compared to the untreated control (Figure 5A). This was verified by no significant alteration in the expression of PARP-1 and effector caspases 3 and 8 (Figures 6A-D and Figure S2.1-3). A significant elevation of apoptotic cells was detected in parental PC3 cells (Figure 5B) even though no significant changes were detected in the chosen proteins responsible for apoptotic signaling (Figures $6 \mathbf{E}-\mathbf{H}$ and Figure S2.4-6). An increase in apoptotic events was observed in both parental and DX-resistant LNCaP cells (Figure 5C). Here, activated apoptotic signaling was confirmed by a significant down-regulation of caspase 3 in DX-resistant LNCaP cells and PARP-1 in both parental and DX-resistant LNCaP cells after 

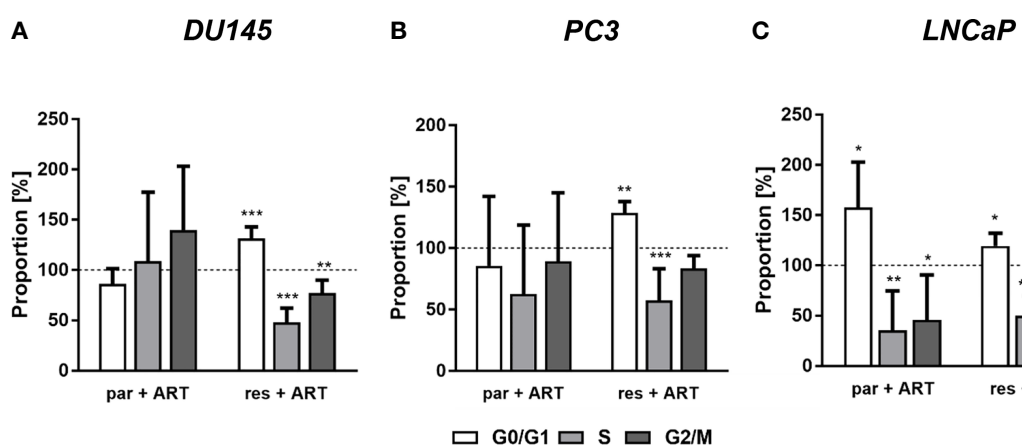

FIGURE 3 | Distribution of cell cycle phases: proportion of parental (par) and DX-resistant (res) PCa cells, DU145 (A), PC3 (B), and LNCaP (C), in the G0/G1, S, and G2/M phases after $48 \mathrm{~h}$ ART application [37.5 $\mathrm{MM}$ ]. Untreated cells served as controls (dotted line set to 100\%). Error bars indicate standard deviation (SD). Significant difference to untreated control: ${ }^{*} p \leq .05,{ }^{* *} p \leq .01,{ }^{* * *} p \leq .001 . n=3$.

exposure to ART (Figures 6I-L and Figure S2.7-9). Necrotic events were generally low and remained unchanged after ART treatment (data not shown).

\subsection{Artesunate Induces Ferroptosis in DU145 But Not in PC3 or LNCaP Cells}

Neither cell cycle progression nor apoptosis was induced in the parental DU145 cells after ART treatment and could explain the observed growth and proliferation inhibition. Since ART has been shown to activate ferroptosis, an alternative iron-dependent cell death $(29,34,35)$, ferroptosis was investigated. Combined application of ART with ferrostatin-1, a ferroptosis inhibitor, significantly counteracted ART's inhibitory effect on proliferation in parental DU145 cells after $24 \mathrm{~h}$ (Figure 7A). This effect indicates that ferroptosis induction in parental DU145 cells contributes to the ART-mediated proliferation block. Also, in DX-resistant DU145 cells ferrostatin-1 application showed significant abrogation of ART's $[37.5 \mu \mathrm{M}]$ anti-proliferative activity after $24 \mathrm{~h}$, although to a lower extent (Figure 7B). The counteracting effect of ferrostatin-1 in the DX-resistant cells further increased after $48 \mathrm{~h}$ (Figure 7D), demonstrating a later activation of ferroptosis in DX-resistant DU145 cells. In contrast, in the parental DU145 cells the proliferation inhibition by ART was no longer significantly impaired, when combined with ferrostatin-1 for $48 \mathrm{~h}$ (Figure 7C), further corroborating the time-shift in ferroptosis-activation in parental and DX-resistant DU145 cells.

However, in parental and DX-resistant PC3 cells, combined ART application with ferrostatin-1 did not affect the efficacy of ART's anti-proliferative activity (Figures 7E-H). Also in parental or DX-resistant LNCaP cells, additive administration of ferrostain-1 had no consequence on the ART-induced reduction of proliferation (Figures $7 \mathbf{I}-\mathbf{L}$ ). Thus, ART induces ferroptosis only in parental and DX-resistant DU145 cells. Therefore, only in these cell lines was the impact of ART on ROS production studied.

To investigate whether ART treatment results in ROS generation, the content of glutathione (GSH) and glutathione peroxidase 4 (GPX4), components of the antioxidant protection mechanism, were determined in ART-treated PCa cells. Biochemically, ferroptosis is characterized by consumption of extracellular GSH and decreased GPX4 levels. Thereby, reduction of GPX4 levels leads to intracellular accumulation of ROS, triggering ferroptosis. Administration of ART in parental and DX-resistant DU145 cells significantly reduced intracellular GSH content, compared to untreated controls, indicating higher GSH consumption and ROS generation (Figure 8A). Moreover, expression of GPX4 was significantly diminished in parental DU145 cells by $37.5 \mu \mathrm{M}$ ART (Figure 8B and Figure S3). Significant down-regulation of GPX4 expression by ART was also observed in DX-resistant DU145 cells, albeit to a lesser extent than in the parental counterpart (Figure 8B and Figure S3).

\section{DISCUSSION}

Despite recent progress, $\mathrm{PCa}$ remains a challenge without curative therapy for metastatic disease. Hence, the desire for complementary and alternative medicine (CAM) has gained widespread interest in the past decades. However, sciencebased knowledge concerning the anti-tumor properties of CAM is still limited. Therefore, the present study was designed to evaluate the therapeutic potential of ART in parental and DXresistant $\mathrm{PCa}$ cell lines. Consistent with previous findings in therapy-sensitive PCa cells DU145, LNCaP (36), and 22rvl (19), a potent and dose-dependent inhibition of cell growth and proliferation by ART was observed. The ART concentrations affecting PCa cells in vitro are clinically relevant, since ART attaining these concentrations has been applied to treat patients with refractory solid tumors (37) and malaria (38). Besides the growth inhibitory effect in parental PCa cells, the current study revealed that ART also induces anti-growth and antiproliferative activity in DX-resistant DU145, PC3, and LNCaP cells. Accordingly, ART disrupted resistance in other cancer types that have become insensitive to conventional therapeutic agents, including bicalutamide, an androgen receptor antagonist, 
A

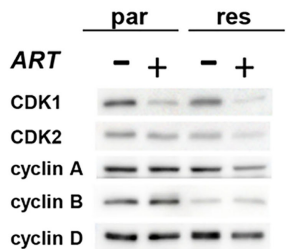

B
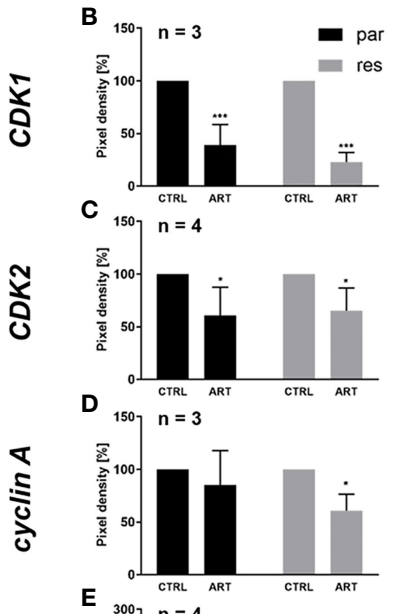

E

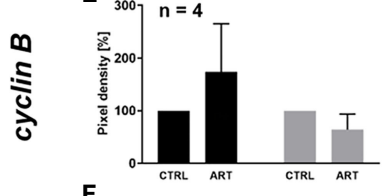

$\mathbf{F}$

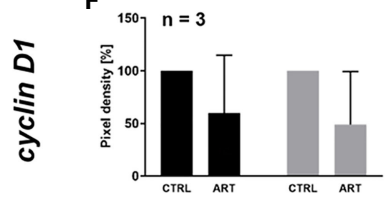

G

PC3

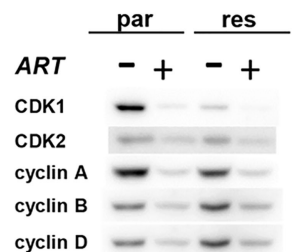

H

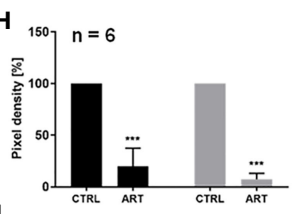

I ${ }^{150}{ }^{\mathrm{CTRL}} \mathrm{n}=6$

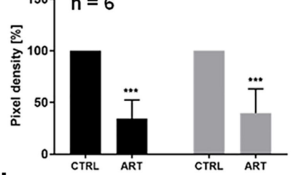

${ }^{150}, n=5$

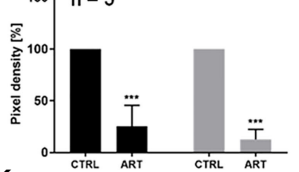

$\mathrm{K}$

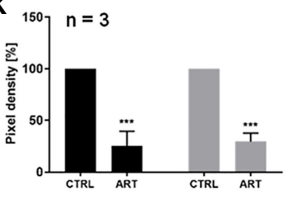

L

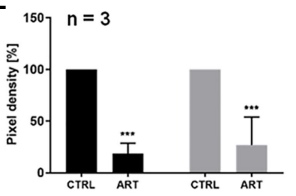

M

LNCaP

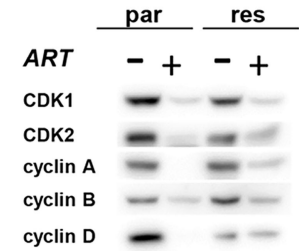

N

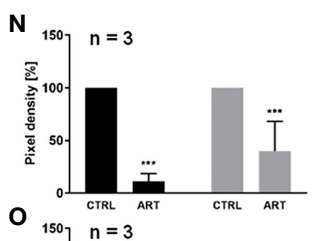

O

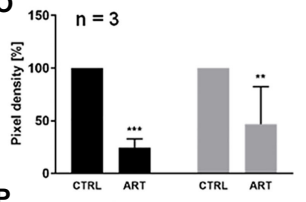

$P_{150}{ }^{\text {CTrL }}=3$

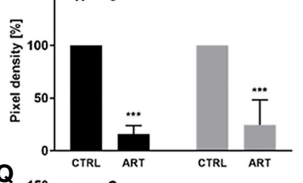

$Q_{150}{ }^{\text {CTRL }} \mathrm{n}=3$

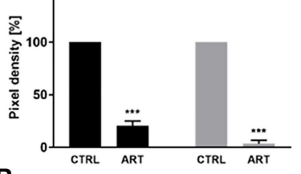

R

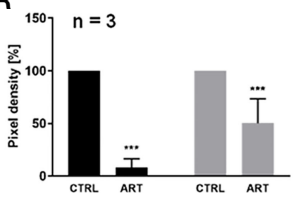

FIGURE 4 | Expression of cell cycle regulating proteins: representative Western blot images of cell cycle regulating proteins in parental (par) and DX-resistant (res) DU145 (A), PC3 (G), and LNCaP (M) cells with (+) and without (-) ART. Pixel density analysis of the expression of cell cycle regu-lating proteins CDK1 (B, H, N), CDK2 (C, I, O), cyclin A (D, J, P), cyclin B (E, K, Q) and cyclin D1 ( $\mathbf{F}, \mathbf{L}, \mathbf{R})$ in parental (par) and DX-resistant (res) cells after $48 \mathrm{~h}$ exposure to ART [37.5 $\mu \mathrm{M}$ ], compared to untreated controls (set to 100\%). Analysis of pixel density was normalized by a total protein staining. Error bars indicate standard deviation (SD). Significant difference to untreated control: ${ }^{*} \mathrm{p} \leq .05,{ }^{\star \star} \mathrm{p} \leq .01,{ }^{\star \star \star} \mathrm{p} \leq .001 . \mathrm{n}=3$. For detailed information regarding the Western blots, see Figures $\mathbf{S 1 . 1 - 1 5}$.

A

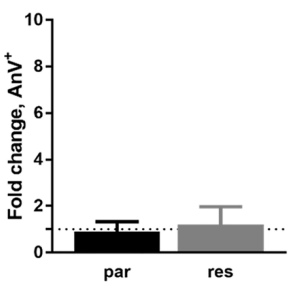

B

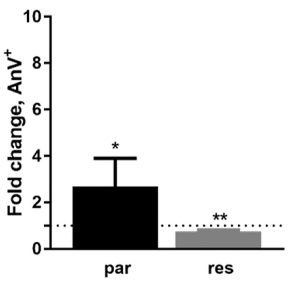

C LNCaP

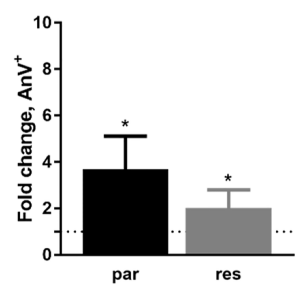

FIGURE 5 | Apoptosis induction: parental (par) and DX-resistant (res) DU145 (A), PC3 (B), and LNCaP (C) cells treated for $48 \mathrm{~h}$ with ART [37.5 $\mu$ M]. The analysis was performed by Annexin $\mathrm{V}(\mathrm{AnV}+) / \mathrm{PI}$ detection (in fold change). Untreated cells served as controls (dotted line, set to 1). Error bars indicate standard deviation (SD). Significant difference to untreated control: ${ }^{*} \mathrm{p} \leq .05,{ }^{\star *} \mathrm{p} \leq .01 . \mathrm{n}=3$. 


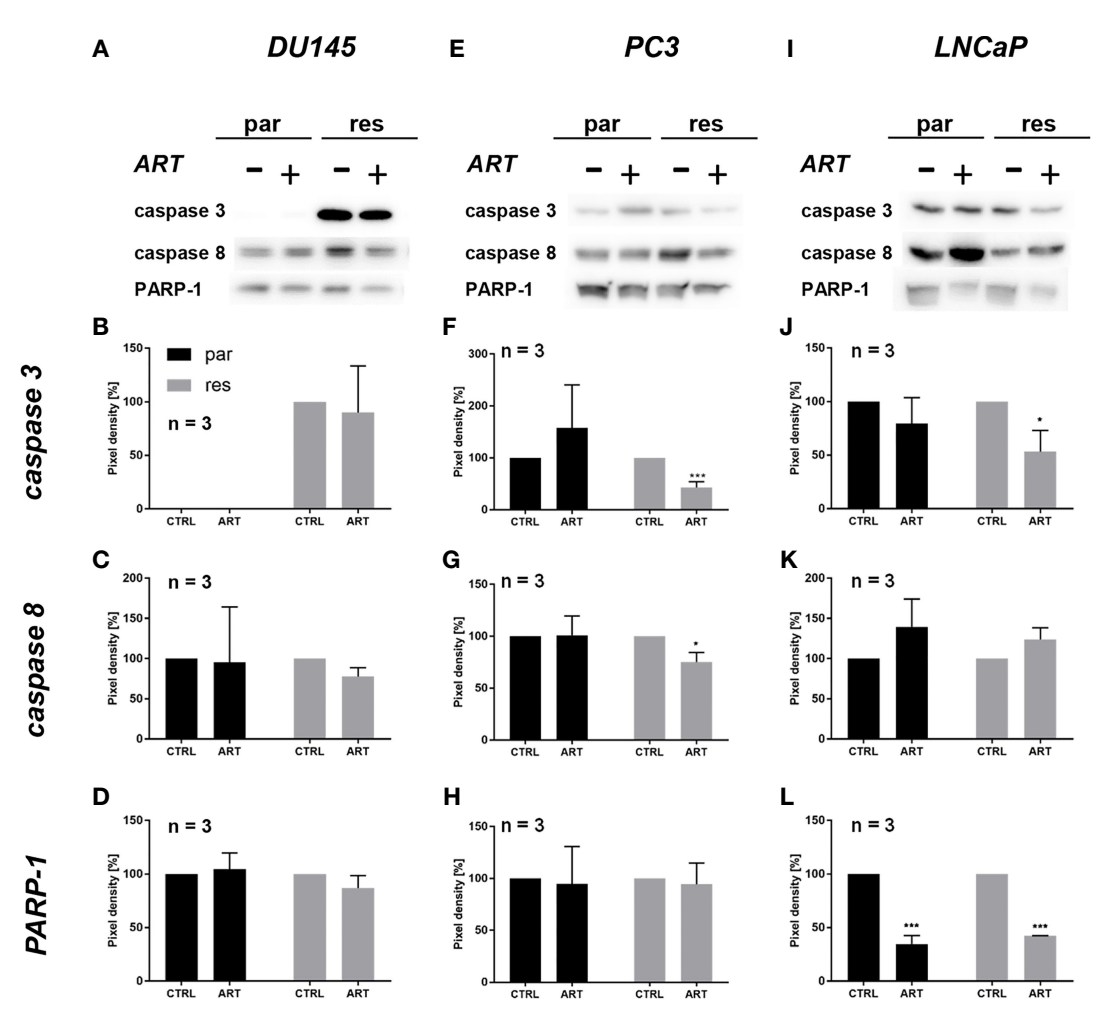

FIGURE 6 | Apoptotic signaling: representative Western blot images of apoptosis-related proteins in parental (par) and DX-resistant (res) DU145 (A), PC3 (E) and LNCaP (I) cells with (+) and without (-) ART. Pixel density of caspase $3(\mathbf{B}, \mathbf{F}, \mathbf{J})$, caspase 8 (C, G, K) and PARP-1 (D, H, L) expression in parental (par) and DXresistant (res) cells. All protein analysis was normalized by a total protein control. Untreated cells served as controls (100\%). Error bars indicate standard deviation (SD). Significant difference indicated by: ${ }^{\star} \mathrm{p} \leq .05,{ }^{* \star} \mathrm{p} \leq .001 . \mathrm{n}=3$. For detailed information regarding the Western blots, see Figures S2.1-9.

applied formerly to treat metastatic castration-resistant prostate cancer (39). Recent studies have demonstrated ART-induced anti-cancer properties in parental and cisplatin-resistant bladder cancers (40) and sunitinib-resistant renal cell carcinomas (41). In line with these observations, ART also inhibited cell growth and proliferation in tongue (42), breast $(43,44)$, liver $(45)$, colorectal (46) and esophageal (47) cancers. Moreover, the present investigation revealed that ART does not restrict the growth of 'normal', here primary non-tumor tubular epithelial, cells.

Reduced cell growth and proliferation of the DX-resistant DU145, PC3, and LNCaP and parental LNCaP cells were associated with G0/G1 phase arrest and a significant reduction of S phase (all) and G2/M phase cells (DU145). Consistent with this, ART-induced anti-proliferative activity was accompanied by an increase in the G0/G1 phase in human epidermoid carcinoma (48), endometrial cancer (49), bladder cancer (40) and renal carcinoma (41) cells. In good accordance with the G0/ G1 phase arrest in the PCa cells, the cell cycle activating proteins CDK1, CDK2, cyclin A, and cyclin B, responsible for $\mathrm{S}$ phase and G2/M phase progression, were down-regulated, further corroborating the G0/G1 phase arrest. DNA replication in the $S$ phase is controlled by the CDK2/cyclin A complex (50) and the activity of the cyclin B/CDK1 complex is required during the G2/ $M$ phase (51). Furthermore, expression of cyclin D1, which is involved in regulating G0/G1 phase progression (52), diminished after exposure to ART.

Apoptotic events occurred in parental PC3 and LNCaP cells as well as in the DX-resistant LNCaP and DU145 cells. In contrast, parental DU145 and DX-resistant PC3 cells did not display apoptotic cell death after $48 \mathrm{~h}$ exposure to ART. Thus, the mechanism behind the ART-induced inhibition of growth and proliferation in parental DU145 initially remained obscure. As a consequence, activation of alternative cell death signaling was postulated and evaluated as a possible explanation for these inhibitory effects of ART. Indeed, ferrostatin-1, a selective ferroptosis inhibitor, significantly abrogated the antiproliferative activity of ART, exclusively in parental and DXresistant DU145 cells, indicating ferroptosis induction. In good accordance with our data, it has been shown that ART efficiently induced ferroptosis in head and neck (28) as well as in pancreas (29) cancer cells. Furthermore, ART activated ferroptosis in hepatocellular carcinoma cells, when combined with sorafenib (53). In contrast, PC3 and LNCaP cells were not affected. In fact, only the DU145 cell line, among the chosen PCa cell lines, carries a mutation in the oncogenic KRAS gene, resulting in a gene fusion with the ubiquitin-conjugating enzyme UBE2L3 (54). Erastin, a specific ferroptosis inducer, caused preferential lethality in cells bearing a point mutation in the oncogenic 
DU145

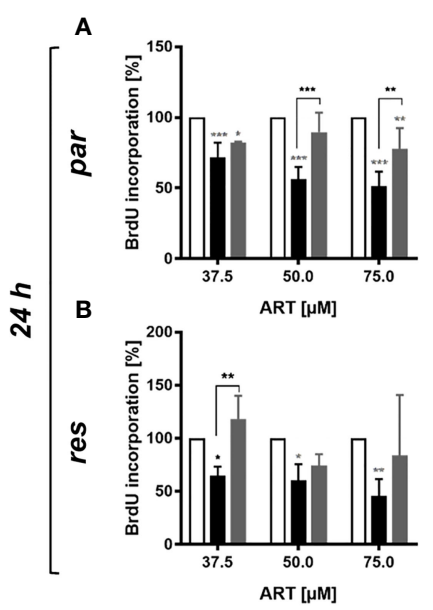

C
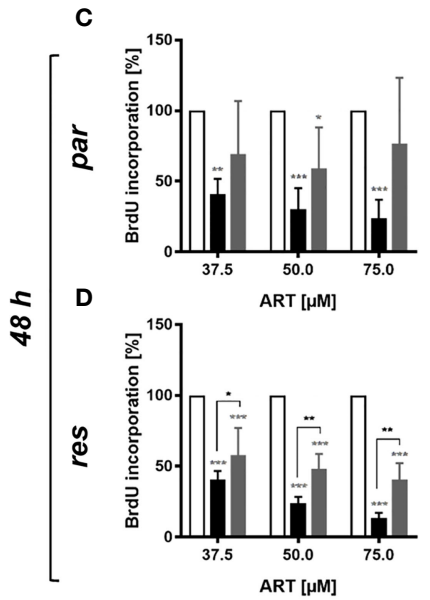
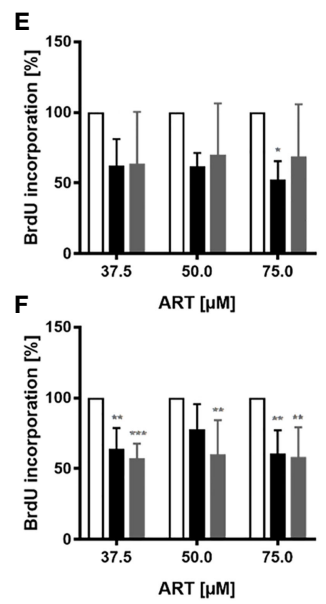

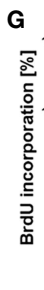
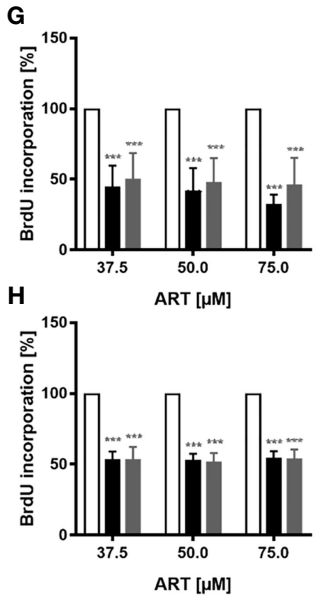

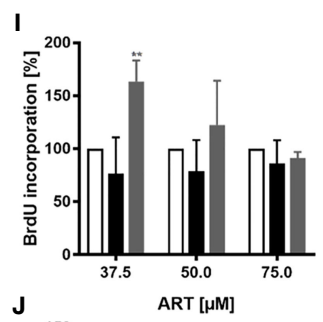

$\sqrt{ }$

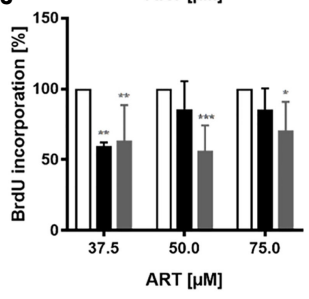

K

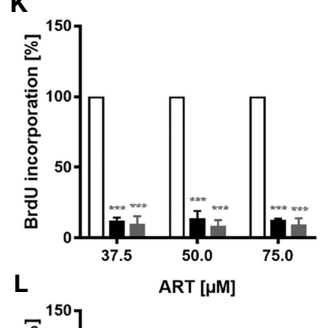

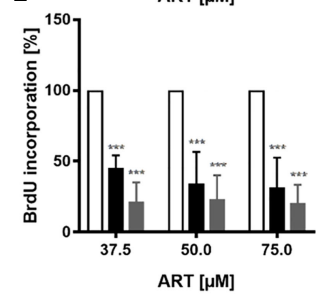

FIGURE 7 | Ferroptosis induction: cell proliferation of parental (par) and DX-resistant (res) DU145, PC3, and LNCaP cells treated for 24 (A, B, E, F, I, J) and 48 h (C, D, G, H, K, L) with ART [37.5 - $75 \mu \mathrm{M}]$, alone or in combination with ferrostatin-1 (Fer-1) [20 $\mu$ M]. Untreated cells (100\%) served as controls. Error bars indicate standard deviation (SD). Asterisk brackets indicate significant difference between ART and ART with ferrostatin-1 treatment. Significant difference compared to untreated controls indicated by: ${ }^{\star} p \leq .05,{ }^{\star \star} p \leq .01,{ }^{\star \star \star} p \leq .001 . n=3$.

HRAS(G12V) gene (55). Thus, the KRAS-UBE2L3 fusion protein might lead to ART-mediated induction of ferroptosis in DU145 cells. However, this is speculative and requires further investigation. In parental DU145 cells additional application of ferrostatin-1 already counteracted ART's anti-proliferative impact after $24 \mathrm{~h}$. A similar effect was evident in DX-resistant DU145 cells after $48 \mathrm{~h}$, indicating a delayed initiation of ferroptosis in the DX-resistant DU145 cells, compared to the parental DU145 cells. This delay might explain the more potent proliferation inhibition after $48 \mathrm{~h}$ ART treatment in the parental, compared to the DX-resistant DU145 cells.

Several studies have indicated that ART induces DNA damage via oxidative stress and the generation of free radicals and reactive oxygen species $(56,57)$. A main feature of ferroptosis is lipid peroxidation of the cellular and organelle membranes, due to elevated intracellular ROS, causing oxidative cell death (58-60). Ferroptosis-mediated ROS is known to be accompanied by a depletion of GSH and the blockade of the antioxidant defense mechanisms with the Systems-xc and GSHdependent peroxidase, GPX4 (58-60). In good accordance with this, in both parental and DX-resistant DU145 cells significantly reduced GSH levels were apparent after exposure to ART, confirming ROS formation under ART administration. Similarly, ART increased ROS and decreased GSH in the most aggressive triple-negative breast cancer cells, resulting in intracellular oxidative imbalance and ferroptosis (61). Furthermore, ART induced ferroptosis in head and neck cancer cells by decreasing cellular GSH levels and increasing lipid ROS levels (28). This effect could be blocked by coincubation with ferrostatin-1. GPX4 catalyzes the reduction of 

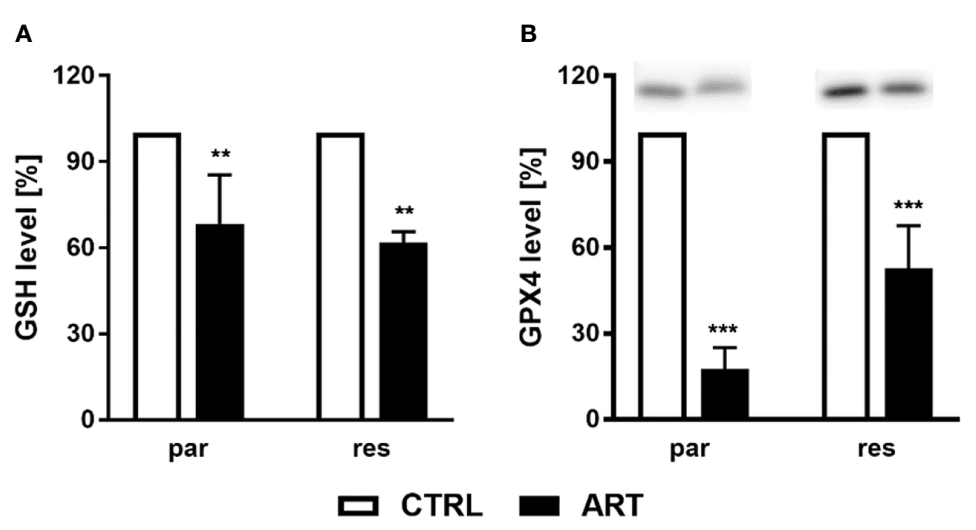

FIGURE 8 | ROS production: GSH level [\%] of DU145 cells after $24 \mathrm{~h}$ incubation with ART [37.5 $\mu$ M], compared to untreated controls (set to 100\%) (A). $\mathrm{n}=3$. Pixel density analysis of the GPX4 expression after exposure to ART [37.5 $\mu \mathrm{M}]$ (B). Error bars indicate standard deviation (SD). Significant difference to untreated controls indicated by: ${ }^{* *} p \leq .01,{ }^{* *} p \leq .001 . n=3$. For detailed information regarding the Western blots, see Figure S3.

GSH to oxidized GSSG, using GSH as an essential cofactor, thereby reducing ROS to $\mathrm{H}_{2} \mathrm{O}$ (62). Silencing GPX4 by shRNA, which leads to a partial knockdown of GPX4, sensitized fibrosarcoma and renal carcinoma cells to a ferroptosisinduced lethality by erastin (63).Consistent with this, the current study revealed a significant decrease of GPX4 expression in both parental and DX-resistant cells after ART treatment, indicating inhibited GPX4 activity accompanied by absent GSH regeneration and therewith accumulation of ROS.

Since the antitumor effects of ART were apparent in both androgen-sensitive (LNCaP) and androgen-insensitive PCa-cells (PC3 \& DU-145), ART's action seems to be androgen receptorindependent. However, an impact on androgen receptors cannot be totally excluded, as its expression was not evaluated. Other investigators have revealed a reduction in androgen receptors after ART treatment in androgen receptor-positive 22rvl cells (19).

\section{CONCLUSIONS}

ART exhibited tumor suppressive potential in regard to the progressive growth of parental and therapy-resistant PCa cells. Cell-type-specific modes of action were induced by ART, leading to cell cycle arrest, apoptosis and/or ferroptosis. These actions were accompanied by impaired expression of cell cycle activating proteins, mainly CDK1, CDK2, cyclin A, cyclin B, and cyclin D1, modulated expression of apoptotic proteins, and an increase in ROS. Therefore, ART may hold promise as a complementary therapeutic option in patients with advanced and even therapyresistant $\mathrm{PCa}$.

\section{DATA AVAILABILITY STATEMENT}

The original contributions presented in the study are included in the article/Supplementary Material. Further inquiries can be directed to the corresponding author.

\section{AUTHOR CONTRIBUTIONS}

Conceptualization, EJ. Methodology, VB, OV, SM, HE, PS, PB, KS, AT, MP, ZC, JC, and MM. Software, SM. Validation, OV and SM. Formal analysis, $\mathrm{VB}$ and $\mathrm{OV}$. Investigation, EJ and $\mathrm{OV}$. Resources, EJ, PB, TE, MP, ZC, JC, and MM. Data curation, OV. Writing-original draft preparation, OV. Writing-review and editing, EJ, HE, IT, AH, TE, and MM. Visualization, OV. Supervision, EJ. Project administration, EJ. Funding acquisition, EJ, MM, and JC. All authors have read and agreed to the published version of the manuscript.

\section{FUNDING}

This research was funded by the Brigitta und Norbert Muth Stiftung, grant number 01/2018 (EJ), Hilfe für krebskranke Kinder Frankfurt e.V. (JCJr.), Frankfurter Stiftung für krebskranke Kinder (JCJr), and the Kent Cancer Trust (MM).

\section{ACKNOWLEDGMENTS}

The main portion of the results presented here are part of the medical doctor thesis of VB. at the Department of Urology and Pediatric Urology (University Medical Center Mainz, Langenbeckstraße 1, 55131 Mainz, Germany). Some elements stem from the master thesis of PS.

\section{SUPPLEMENTARY MATERIAL}

The Supplementary Material for this article can be found online at: https://www.frontiersin.org/articles/10.3389/fonc.2022. 789284/full\#supplementary-material 


\section{REFERENCES}

1. Sanda MG, Cadeddu JA, Kirkby E, Chen RC, Crispino T, Fontanarosa J, et al. Clinically Localized Prostate Cancer: AUA/ASTRO/SUO Guideline. Part I: Risk Stratification, Shared Decision Making, and Care Options. J Urol (2018) 199:683-90. doi: 10.1016/j.juro.2017.11.095

2. Mohler JL, Antonarakis ES. NCCN Guidelines Updates: Management of Prostate Cancer. J Natl Compr Canc Netw (2019) 17:583-6. doi: 10.6004/ jnccn.2019.5011

3. Parker C, Castro E, Fizazi K, Heidenreich A, Ost P, Procopio G, et al. Clinicalguidelines@Esmo.Org, E.G.C.E.a. Prostate Cancer: ESMO Clinical Practice Guidelines for Diagnosis, Treatment and Follow-Up. Ann Oncol (2020) 31:1119-34. doi: 10.1016/j.annonc.2020.06.011

4. Clarke NW, Ali A, Ingleby FC, Hoyle A, Amos CL, Attard G, et al. Addition of Docetaxel to Hormonal Therapy in Low- and High-Burden Metastatic Hormone Sensitive Prostate Cancer: Long-Term Survival Results From the STAMPEDE Trial. Ann Oncol (2019) 30:1992-2003. doi: 10.1093/annonc/mdz396

5. Heck MM, Thalgott M, Retz M, Wolf P, Maurer T, Nawroth R, et al. Rational Indication for Docetaxel Rechallenge in Metastatic Castration-Resistant Prostate Cancer. BJU Int (2012) 110:E635-640. doi: 10.1111/j.1464410X.2012.11364.x

6. Thomas C, Brandt MP, Baldauf S, Tsaur I, Frees S, Borgmann H, et al. DocetaxelRechallenge in Castration-Resistant Prostate Cancer: Defining Clinical Factors for Successful Treatment Response and Improvement in Overall Survival. Int Urol Nephrol (2018) 50:1821-7. doi: 10.1007/s11255-018-1963-1

7. Cornford P, van den Bergh RCN, Briers E, Van den Broeck T, Cumberbatch MG, De Santis M, et al. EAU-EANM-ESTRO-ESUR-SIOG Guidelines on Prostate Cancer. Part II-2020 Update: Treatment of Relapsing and Metastatic Prostate Cancer. Eur Urol (2021) 79:263-82. doi: 10.1016/j.eururo.2020.09.046

8. Cornford P, Bellmunt J, Bolla M, Briers E, De Santis M, Gross T, et al. EAUESTRO-SIOG Guidelines on Prostate Cancer. Part II: Treatment of Relapsing, Metastatic, and Castration-Resistant Prostate Cancer. Eur Urol (2017) 71:630-42. doi: 10.1016/j.eururo.2016.08.002

9. Jang A, Kang DH, Kim DU. Complementary and Alternative Medicine Use and Its Association With Emotional Status and Quality of Life in Patients With a Solid Tumor: A Cross-Sectional Study. J Altern Complement Med (2017) 23:362-9. doi: 10.1089/acm.2016.0289

10. Hierl M, Pfirstinger J, Andreesen R, Holler E, Mayer S, Wolff D, et al. Complementary and Alternative Medicine: A Clinical Study in 1,016 Hematology/Oncology Patients. Oncology (2017) 93:157-63. doi: 10.1159/ 000464248

11. Ebel MD, Rudolph I, Keinki C, Hoppe A, Muecke R, Micke O, et al. Perception of Cancer Patients of Their Disease, Self-Efficacy and Locus of Control and Usage of Complementary and Alternative Medicine. J Cancer Res Clin Oncol (2015) 141:1449-55. doi: 10.1007/s00432-015-1940-3

12. Kessel KA, Lettner S, Kessel C, Bier H, Biedermann T, Friess H, et al. Use of Complementary and Alternative Medicine (CAM) as Part of the Oncological Treatment: Survey About Patients' Attitude Towards CAM in a UniversityBased Oncology Center in Germany. PloS One (2016) 11:e0165801. doi: 10.1371/journal.pone.0165801

13. Sauter ER. Cancer Prevention and Treatment Using Combination Therapy With Natural Compounds. Expert Rev Clin Pharmacol (2020) 13:265-85. doi: $10.1080 / 17512433.2020 .1738218$

14. Hsu E. The History of Qing Hao in the Chinese Materia Medica. Trans R Soc Trop Med Hyg (2006) 100:505-8. doi: 10.1016/j.trstmh.2005.09.020

15. Efferth T. From Ancient Herb to Modern Drug: Artemisia Annua and Artemisinin for Cancer Therapy. Semin Cancer Biol (2017) 46:65-83. doi: 10.1016/j.semcancer.2017.02.009

16. Sarma B, Willmes C, Angerer L, Adam C, Becker JC, Kervarrec T, et al. Artesunate Affects T Antigen Expression and Survival of Virus-Positive Merkel Cell Carcinoma. Cancers (Basel) (2020) 12:919. doi: 10.3390/cancers12040919

17. Morrissey C, Gallis B, Solazzi JW, Kim BJ, Gulati R, Vakar-Lopez F, et al. Effect of Artemisinin Derivatives on Apoptosis and Cell Cycle in Prostate Cancer Cells. Anticancer Drugs (2010) 21:423-32. doi: 10.1097/CAD. 0b013e328336f57b

18. Willoughby JASr., Sundar SN, Cheung M, Tin AS, Modiano J, Firestone GL. Artemisinin Blocks Prostate Cancer Growth and Cell Cycle Progression by Disrupting Sp1 Interactions With the Cyclin-Dependent Kinase-4 (CDK4)
Promoter and Inhibiting CDK4 Gene Expression. J Biol Chem (2009) 284:2203-13. doi: 10.1074/jbc.M804491200

19. Wang Z, Wang C, Wu Z, Xue J, Shen B, Zuo W, et al. Artesunate Suppresses the Growth of Prostatic Cancer Cells Through Inhibiting Androgen Receptor. Biol Pharm Bull (2017) 40:479-85. doi: 10.1248/bpb.b16-00908

20. Ng DS, Liao W, Tan WS, Chan TK, Loh XY, Wong WS. Anti-Malarial Drug Artesunate Protects Against Cigarette Smoke-Induced Lung Injury in Mice. Phytomedicine (2014) 21:1638-44. doi: 10.1016/j.phymed.2014.07.018

21. Posner GH, Oh CH, Gerena L, Milhous WK. Extraordinarily Potent Antimalarial Compounds: New, Structurally Simple, Easily Synthesized, Tricyclic 1,2,4-Trioxanes. J Med Chem (1992) 35:2459-67. doi: 10.1021/ jm00091a014

22. Zhang S, Gerhard GS. Heme Mediates Cytotoxicity From Artemisinin and Serves as a General Anti-Proliferation Target. PloS One (2009) 4:e7472. doi: 10.1371/journal.pone.0007472

23. Peng Q, Warloe T, Berg K, Moan J, Kongshaug M, Giercksky KE, et al. 5Aminolevulinic Acid-Based Photodynamic Therapy. Clinical Research and Future Challenges. Cancer (1997) 79:2282-308. doi: 10.1002/(sici)1097-0142 (19970615)79:12<2282::aid-cncr2>3.0.co;2-o

24. Hamacher-Brady A, Stein HA, Turschner S, Toegel I, Mora R, Jennewein N, et al. Artesunate Activates Mitochondrial Apoptosis in Breast Cancer Cells via Iron-Catalyzed Lysosomal Reactive Oxygen Species Production. J Biol Chem (2011) 286:6587-601. doi: 10.1074/jbc.M110.210047

25. Efferth T, Giaisi M, Merling A, Krammer PH, Li-Weber M. Artesunate Induces ROS-Mediated Apoptosis in Doxorubicin-Resistant T Leukemia Cells. PloS One (2007) 2:e693. doi: 10.1371/journal.pone.0000693

26. Michaelis M, Kleinschmidt MC, Barth S, Rothweiler F, Geiler J, Breitling R, et al. Anti-Cancer Effects of Artesunate in a Panel of Chemoresistant Neuroblastoma Cell Lines. Biochem Pharmacol (2010) 79:130-6. doi: 10.1016/j.bcp.2009.08.013

27. Greenshields AL, Shepherd TG, Hoskin DW. Contribution of Reactive Oxygen Species to Ovarian Cancer Cell Growth Arrest and Killing by the Anti-Malarial Drug Artesunate. Mol Carcinog (2017) 56:75-93. doi: 10.1002/mc.22474

28. Roh JL, Kim EH, Jang H, Shin D. Nrf2 Inhibition Reverses the Resistance of Cisplatin-Resistant Head and Neck Cancer Cells to Artesunate-Induced Ferroptosis. Redox Biol (2017) 11:254-62. doi: 10.1016/j.redox.2016.12.010

29. Eling N, Reuter L, Hazin J, Hamacher-Brady A, Brady NR. Identification of Artesunate as a Specific Activator of Ferroptosis in Pancreatic Cancer Cells. Oncoscience (2015) 2:517-32. doi: 10.18632/oncoscience.160

30. Baer PC, Bereiter-Hahn J, Schubert R, Geiger H. Differentiation Status of Human Renal Proximal and Distal Tubular Epithelial Cells In Vitro: Differential Expression of Characteristic Markers. Cells Tissues Organs (2006) 184:16-22. doi: 10.1159/000096947

31. Baer PC, Nockher WA, Haase W, Scherberich JE. Isolation of Proximal and Distal Tubule Cells From Human Kidney by Immunomagnetic Separation. Technical Note. Kidney Int (1997) 52:1321-31. doi: 10.1038/ki.1997.457

32. Michaelis M, Rothweiler F, Barth S, Cinatl J, van Rikxoort M, Loschmann N, et al. Adaptation of Cancer Cells From Different Entities to the MDM2 Inhibitor Nutlin-3 Results in the Emergence of P53-Mutated Multi-Drug-Resistant Cancer Cells. Cell Death Dis (2011) 2:e243. doi: 10.1038/cddis.2011.129

33. Michaelis M, Wass MN, Cinatl J. Drug-Adapted Cancer Cell Lines as Preclinical Models of Acquired Resistance. Cancer Drug Resistance (2019) 2:447-56. doi: 10.20517/cdr.2019.005

34. Kong Z, Liu R, Cheng Y. Artesunate Alleviates Liver Fibrosis by Regulating Ferroptosis Signaling Pathway. BioMed Pharmacother (2019) 109:2043-53. doi: 10.1016/j.biopha.2018.11.030

35. Ooko E, Saeed ME, Kadioglu O, Sarvi S, Colak M, Elmasaoudi K, et al. Artemisinin Derivatives Induce Iron-Dependent Cell Death (Ferroptosis) in Tumor Cells. Phytomedicine (2015) 22:1045-54. doi: 10.1016/j.phymed. 2015.08.002

36. Zhou Y, Wang X, Zhang J, He A, Wang YL, Han K, et al. Artesunate Suppresses the Viability and Mobility of Prostate Cancer Cells Through UCA1, the Sponge of Mir-184. Oncotarget (2017) 8:18260-70. doi: 10.18632/oncotarget.15353

37. Deeken JF, Wang H, Hartley M, Cheema AK, Smaglo B, Hwang JJ, et al. A Phase I Study of Intravenous Artesunate in Patients With Advanced Solid Tumor Malignancies. Cancer Chemother Pharmacol (2018) 81:587-96. doi: $10.1007 / \mathrm{s} 00280-018-3533-8$ 
38. Deutsche Gesellschaft für Tropenmedizin, R.u.G.G.e.V.D. Leitlinie: Diagnostik und Therapie der Malaria. Availabe online: https://www.awmf. org/leitlinien/detail/l1/042-001.html (accessed on 20.01.2022).

39. Nunes JJ, Pandey SK, Yadav A, Goel S, Ateeq B. Targeting NF-Kappa B Signaling by Artesunate Restores Sensitivity of Castrate-Resistant Prostate Cancer Cells to Antiandrogens. Neoplasia (2017) 19:333-45. doi: 10.1016/j.neo.2017.02.002

40. Zhao F, Vakhrusheva O, Markowitsch SD, Slade KS, Tsaur I, Cinatl JJr., et al. Artesunate Impairs Growth in Cisplatin-Resistant Bladder Cancer Cells by Cell Cycle Arrest, Apoptosis and Autophagy Induction. Cells (2020) 9:2643. doi: 10.3390/cells9122643

41. Markowitsch SD, Schupp P, Lauckner J, Vakhrusheva O, Slade KS, Mager R, et al. Artesunate Inhibits Growth of Sunitinib-Resistant Renal Cell Carcinoma Cells Through Cell Cycle Arrest and Induction of Ferroptosis. Cancers (Basel) (2020) 12:3150. doi: 10.3390/cancers 12113150

42. Xiao Q, Yang L, Hu H, Ke Y. Artesunate Targets Oral Tongue Squamous Cell Carcinoma via Mitochondrial Dysfunction-Dependent Oxidative Damage and Akt/AMPK/Mtor Inhibition. J Bioenerg Biomembr (2020) 52:113-21. doi: 10.1007/s10863-020-09823-x

43. Chen K, Shou LM, Lin F, Duan WM, Wu MY, Xie X, et al. Artesunate Induces G2/M Cell Cycle Arrest Through Autophagy Induction in Breast Cancer Cells. Anticancer Drugs (2014) 25:652-62. doi: 10.1097/CAD.0000000000000089

44. Greenshields AL, Fernando W, Hoskin DW. The Anti-Malarial Drug Artesunate Causes Cell Cycle Arrest and Apoptosis of Triple-Negative MDA-MB-468 and HER2-Enriched SK-BR-3 Breast Cancer Cells. Exp Mol Pathol (2019) 107:10-22. doi: 10.1016/j.yexmp.2019.01.006

45. Li H, Xu K, Pian G, Sun S. Artesunate and Sorafenib: Combinatorial Inhibition of Liver Cancer Cell Growth. Oncol Lett (2019) 18:4735-43. doi: $10.3892 /$ ol.2019.10810

46. Jiang F, Zhou JY, Zhang D, Liu MH, Chen YG. Artesunate Induces Apoptosis and Autophagy in HCT116 Colon Cancer Cells, and Autophagy Inhibition Enhances the Artesunateinduced Apoptosis. Int J Mol Med (2018) 42:1295304. doi: $10.3892 / \mathrm{ijmm} .2018 .3712$

47. Fei Z, Gu W, Xie R, Su H, Jiang Y. Artesunate Enhances Radiosensitivity of Esophageal Cancer Cells by Inhibiting the Repair of DNA Damage. J Pharmacol Sci (2018) 138:131-7. doi: 10.1016/j.jphs.2018.09.011

48. Jiang Z, Chai J, Chuang HH, Li S, Wang T, Cheng Y, et al. Artesunate Induces G0/G1 Cell Cycle Arrest and Iron-Mediated Mitochondrial Apoptosis in A431 Human Epidermoid Carcinoma Cells. Anticancer Drugs (2012) 23:60613. doi: $10.1097 / \mathrm{CAD} .0 \mathrm{~b} 013 \mathrm{e} 328350 \mathrm{e} 8 \mathrm{ac}$

49. Tran KQ, Tin AS, Firestone GL. Artemisinin Triggers a G1 Cell Cycle Arrest of Human Ishikawa Endometrial Cancer Cells and Inhibits Cyclin-Dependent Kinase-4 Promoter Activity and Expression by Disrupting Nuclear FactorKappab Transcriptional Signaling. Anticancer Drugs (2014) 25:270-81. doi: 10.1097/CAD.0000000000000054

50. Zhang H, Kobayashi R, Galaktionov K, Beach D. p19Skp1 and p45Skp2 Are Essential Elements of the Cyclin a-CDK2 s Phase Kinase. Cell (1995) 82:91525. doi: 10.1016/0092-8674(95)90271-6

51. Gavet O, Pines J. Progressive Activation of Cyclinb1-Cdk1 Coordinates Entry to Mitosis. Dev Cell (2010) 18:533-43. doi: 10.1016/j.devcel.2010.02.013

52. Qie S, Diehl JA. Cyclin D1, Cancer Progression, and Opportunities in Cancer Treatment. J Mol Med (Berl) (2016) 94:1313-26. doi: 10.1007/s00109-016-1475-3

53. Li ZJ, Dai HQ, Huang XW, Feng J, Deng JH, Wang ZX, et al. Artesunate Synergizes With Sorafenib to Induce Ferroptosis in Hepatocellular Carcinoma. Acta Pharmacol Sin (2021) 42:301-10. doi: 10.1038/s41401-020-0478-3
54. Wang XS, Shankar S, Dhanasekaran SM, Ateeq B, Sasaki AT, Jing X, et al. Characterization of KRAS Rearrangements in Metastatic Prostate Cancer. Cancer Discovery (2011) 1:35-43. doi: 10.1158/2159-8274.CD-10-0022

55. Dolma S, Lessnick SL, Hahn WC, Stockwell BR. Identification of GenotypeSelective Antitumor Agents Using Synthetic Lethal Chemical Screening in Engineered Human Tumor Cells. Cancer Cell (2003) 3:285-96. doi: 10.1016/ s1535-6108(03)00050-3

56. Beccafico S, Morozzi G, Marchetti MC, Riccardi C, Sidoni A, Donato R, et al. Artesunate Induces ROS- and P38 MAPK-Mediated Apoptosis and Counteracts Tumor Growth In Vivo in Embryonal Rhabdomyosarcoma Cells. Carcinogenesis (2015) 36:1071-83. doi: 10.1093/carcin/bgv098

57. Gopalakrishnan AM, Kumar N. Antimalarial Action of Artesunate Involves DNA Damage Mediated by Reactive Oxygen Species. Antimicrob Agents Chemother (2015) 59:317-25. doi: 10.1128/AAC.03663-14

58. Dixon SJ, Patel DN, Welsch M, Skouta R, Lee ED, Hayano M, et al. Pharmacological Inhibition of Cystine-Glutamate Exchange Induces Endoplasmic Reticulum Stress and Ferroptosis. Elife (2014) 3:e02523. doi: 10.7554/eLife. 02523

59. Dixon SJ, Lemberg KM, Lamprecht MR, Skouta R, Zaitsev EM, Gleason CE, et al. Ferroptosis: An Iron-Dependent Form of Nonapoptotic Cell Death. Cell (2012) 149:1060-72. doi: 10.1016/j.cell.2012.03.042

60. Angeli JPF, Shah R, Pratt DA, Conrad M. Ferroptosis Inhibition: Mechanisms and Opportunities. Trends Pharmacol Sci (2017) 38:489-98. doi: 10.1016/ j.tips.2017.02.005

61. Li Z, Wu X, Wang W, Gai C, Zhang W, Li W, et al. Fe(II) and Tannic AcidCloaked MOF as Carrier of Artemisinin for Supply of Ferrous Ions to Enhance Treatment of Triple-Negative Breast Cancer. Nanoscale Res Lett (2021) 16:37. doi: 10.1186/s11671-021-03497-z

62. Brigelius-Flohe R, Maiorino M. Glutathione Peroxidases. Biochim Biophys Acta (2013) 1830:3289-303. doi: 10.1016/j.bbagen.2012.11.020

63. Yang WS, SriRamaratnam R, Welsch ME, Shimada K, Skouta R, Viswanathan VS, et al. Regulation of Ferroptotic Cancer Cell Death by GPX4. Cell (2014) 156:317-31. doi: 10.1016/j.cell.2013.12.010

Conflict of Interest: The authors declare that the research was conducted in the absence of any commercial or financial relationships that could be construed as a potential conflict of interest.

Publisher's Note: All claims expressed in this article are solely those of the authors and do not necessarily represent those of their affiliated organizations, or those of the publisher, the editors and the reviewers. Any product that may be evaluated in this article, or claim that may be made by its manufacturer, is not guaranteed or endorsed by the publisher.

Copyright (๑ 2022 Vakhrusheva, Erb, Bräunig, Markowitsch, Schupp, Baer, Slade, Thomas, Tsaur, Puhr, Culig, Cinath, Michaelis, Efferth, Haferkamp and Juengel. This is an open-access article distributed under the terms of the Creative Commons Attribution License (CC BY). The use, distribution or reproduction in other forums is permitted, provided the original author $(s)$ and the copyright owner(s) are credited and that the original publication in this journal is cited, in accordance with accepted academic practice. No use, distribution or reproduction is permitted which does not comply with these terms. 